\title{
Corneal structure in tilted disc syndrome
}

\author{
Estrutura da córnea na síndrome de disco inclinado
}

Abuzer Gunduz ${ }^{1}$, Nihat Polat ${ }^{1}$, Tongabay Cumurcu ${ }^{1}$, ErsinErsan Demirel $^{1}$, Ercan Özsoy ${ }^{1}$

\begin{abstract}
Purpose: To evaluate the central corneal thickness (CCT), corneal volume (CV), and anterior and posterior corneal surfaces using the Scheimpflug imaging system in patients diagnosed with tilted disc syndrome (TDS).

Methods: The study group (Group 1) and the control group (Group 2) comprised 35 eyes of 35 age-, sex-, and refraction-matched cases. All cases underwent a full ophthalmic examination that included cycloplegic refraction, axial ocular length measurement, and Scheimpflug imaging.

Results: The mean age was $34.68 \pm 15.48$ years in Group 1 and $34.11 \pm 12.01$ years in Group $2(p=0.864)$. The gender distribution was 18 males and 17 females in Group 1 and 16 males and 19 females in Group $2(p=0.618$ ). All subjects were Caucasian. The spherical equivalent was 3.62 $\pm 1.75 \mathrm{D}$ in Group 1 and $3.69 \pm 1.51 \mathrm{D}$ in Group $2(p=0.850)$. There was no significant difference in age, sex, race, or spherical equivalent between groups. There was no significant difference in mean keratometric value and CV3 (the CV in the central $3 \mathrm{~mm}$ ) between groups $(p=0.232$ and 0.172 , respectively). There were statistically significant differences in CCT, CV5 and $\mathrm{CV} 7$ ( $\mathrm{CV}$ in the central 5 and $7 \mathrm{~mm}^{3}$, respectively) and total $\mathrm{CV}$ between groups $(p=0.008,0.003,0.023$, and 0.019 , respectively). The values of all parameters were lower in the study group than in the control group. There was also a statistically significant difference in the anterior elevation parameters of the cornea between groups $(p<0.05)$. The mean values of Group 1 were higher than those of Group 2. There were statistically significant differences in the two parameters referring to the posterior elevation of the cornea between the two groups $(p<0.05)$.
\end{abstract}

Conclusion: The results of this study showed that eyes with TDS have thinner CCT, lower CV, and different anterior corneal curvature than normal eyes.

Keywords: Corneal topography; Cornea/pathology; Optic disk/abnormalities; Diagnostic techniques, ophthalmological

\section{RESUMO}

Objetivo: Avaliar a espessura central da córnea (CCT), o volume de córnea (CV), e a superfície corneana anterior e posterior utilizando sistema de imagem Scheimpflug em pacientes com diagnóstico de síndrome do disco inclinado (TDS).

Métodos: 0 grupo de estudo (grupo 1) e o grupo controle (grupo 2) consistiu de 35 olhos de 35 pacientes pareados por idade, sexo e refração em cada grupo. Todos os casos foram submetidos a um exame oftalmológico completo incluindo refração sob cicloplegia, medida do comprimento axial ocular e avaliação por Scheimpflug. Resultados: A idade média foi de 34,68 \pm 15,48 anos no grupo 1 e $34.11 \pm 12,01$ anos no grupo $2(p=0,864)$. A distribuição por sexo foi de 18 homens e 17 mulheres do grupo 1 e 16 homens e 19 mulheres no grupo 2 ( $p=0,618$ ). Todos os indivíduos eram caucasianos. O equivalente esférico foi 3,62 $\pm 1,75$ D no Grupo 1 e 3,69 \pm 1,51 D no Grupo $2(p=0,850)$. Não houve diferença significativa entre os dois grupos para idade, sexo, raça e equivalente esférico. Não houve diferença significativa entre os dois grupos para o valor médio ceratométrico e CV3 (o volume da córnea na central $3 \mathrm{~mm}$ ) $(p=0,232, p=0,172$, respectivamente). Houve diferença estatisticamente significativa entre os dois grupos para CCT, CV5, CV7 (volume de córnea na região central 5 e $7 \mathrm{~mm}$, respectivamente) e CV total ( $p=0,008, p=0,003, p=0,023$ e $p=0,019$, respectivamente). Os valores do grupo de estudo foram menores do que o grupo controle para todos os parâmetros. Houve também diferença estatisticamente significativa entre os dois grupos nos parâmetros elevação anterior da córnea $(p<0,05)$. Os valores médios do grupo 1 foram maiores do que o grupo 2. Não houve diferença entre os dois grupos para os dois parâmetros referentes à elevação posterior da córnea $(p<0,05)$.

Conclusões: Nosso estudo mostrou que os olhos com TDS apresentam CCT mais fina, menor volume da córnea e alterações na curvatura corneana anterior quando comparados aos olhos normais.

Descritores: Topografia da córnea; Córnea/patologia; Disco óptico/anormalidades; Técnicas de diagnóstico oftalmológico

\section{INTRODUCTION}

Tilted disc syndrome (TDS) is a nonhereditary syndrome characterized by a congenital optic disc abnormality with an elevation of the superotemporal part and depression of the inferonasal part of the disc, leading to an oblique orientation of its longitudunal axis that affects males and females equally ${ }^{(1,2)}$. Situs inversus (oblique orientation of retinal vascular structures), myopic astigmatism, peripapillary atrophy, ectasic inferonazal fundus, inferior retinal pigment epithelium, and choroid thinning are frequently present in these cases ${ }^{(1,2)}$. These findings can be associated with bitemporal hemianopsia, central retinal vein thrombosis, peripapillary subretinal hemorrhage, macular neurosensory retinal detachment, and secondary choroidal neovascularization ${ }^{(3,4)}$. Myopic astigmatism, which has been reported to be mainly corneal in origin, is the main cause of poor vision in TDS patients ${ }^{(5)}$. Another study reported clinically significant lenticular astigmatism in these $\operatorname{cases}^{(3)}$. A marked relationship between abnormal corneal configuration and abnormal optic discs has been reported in the literature. Another study reported that the orientation of the long axis of the optic disk could indicate the corneal astigmatism axis ${ }^{(6)}$, and Pakravan et al. ${ }^{(7)}$ reported an inverse correlation between the optic disk area and central corneal thickness (CCT).

The Scheimpflug imaging system (Pentacam) provides data on the elevation of the anterior and posterior corneal aspects, and pachymetric measurements without making contact with the ocular surface using a procedure that is easy to perform and repeatable. The Scheimpflug imaging system also provides user-independent high reliability ${ }^{(8)}$.
Submitted for publication: December 4, 2014

Accepted for publication: May 27, 2016

${ }^{1}$ Department of Ophthalmology, School of Medicine, Inonu University, Malatya, Turkey.
Funding: No specific financial support was received for this study.

Disclosure of potential conflicts of interest: None of the authors have any potential conflict of interest to disclose.

Corresponding author: Abuzer Gunduz. Inonu University School of Medicine. Malatya 44280 Turkey - E-mail: abuzergunduz@hotmail.com

Approved by the following research ethics committee: Malatya Clinical Studies Ethic Committee (\#2012/57) 
The aim of this study was to evaluate the detailed structure of the cornea in patients with a diagnosis of TDS using the Scheimplug imaging system and to compare these data with those of a normal population. The difference between this study and other previous studies is the use of the Scheimpflug imaging system to evaluate the anterior and posterior surfaces and the volume of the cornea in detail.

\section{METHODS}

The study protocol was approved by the Ethics Committee of Inonu University (Malatya, Turkey). All patients participated in the study voluntarily. Information and consent forms were obtained from the patients and volunteers in the control group.

This was a cross-sectional study conducted between May 2012 and December 2012 that included one eye from each participant. The eye with a spherical equivalent closer to the control group in bilateral cases was chosen. Patients diagnosed with TDS and control cases were recruited from approximately 1350 patients who presented to the Department of Ophthalmology, School of Medicine, Inonu University. The patients and controls were aged 18-60 years with no ocular or corneal pathology or history of ocular surgery, use of any topical or systemic drugs in the last 3 months, or systemic disorder (diabetes mellitus, rheumatologic diseases, Down syndrome, pregnancy) that could affect the eyes. The cases were evaluated as two groups in the study. Power analysis showed that the minimum number of cases for each group was 32 .

The study group (Group 1) consisted of 35 eyes of 35 patients with TDS. The following criteria were used for a diagnosis of TDS: elevation of the superotemporal part and backwards dislocation of the inferonasal part of the optic disc, oblique orientation of the longitudinal axis of the optic disc, the presence of retinal pigment epithelium and choroidal atrophy together with inferonasal peripapillary atrophy (Figure 1). The fundus of all study participants was photographed.

The control group (Group 2) consisted of 35 eyes of 35 age- and sex-matched healthy patients chosen according to spherical equivalents. We made sure that the cycloplegic refraction spherical equivalent value (calculated by adding half the minus astigmatism value to the spherical value) of the control group was similar to that of the study group. Also, the same exclusion criteria were used for the control group and the study group.

An ophthalmologist performed standard ophthalmic examinations of participants in both groups that included refraction, best cor-

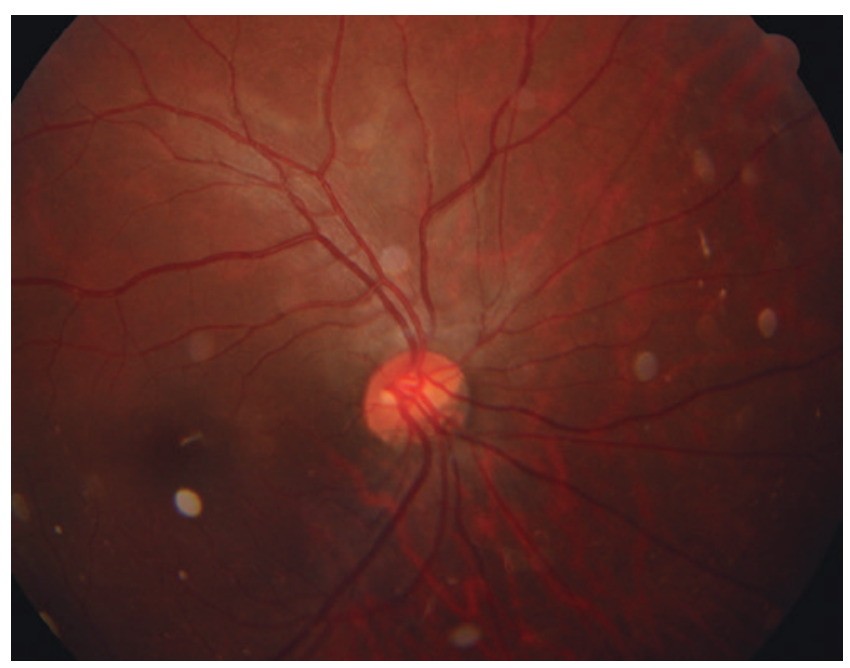

Figure 1. An optic disc image of a 32-year-old male TDS patient with a spherical equivalent of -3.25 diopter rected visual acuity (BCVA), cornea and anterior segment evaluation with a slit lamp, and intraocular pressure (IOP) measurements. Only patients with no pathology were included in the study. All eyes were evaluated with the Scheimpflug imaging system (Oculus Optikgerate $\mathrm{GmbH}$, Wetzlar, Germany) and axial length measurement and cycloplegic refraction were performed with an auto kerato-refractometer (KR-8900; Topcon Corporation, Tokyo, Japan) 45 min after administration of 1\% cyclopentolate hydrochloride drops at 10-min intervals.

Both groups consisted of patients with no systemic disease who had not used any systemic or topical drugs in the last 3 months. Patients who underwent ocular surgery, had a history of contact lens use, had ocular trauma, or had symptoms of ocular allergy or dry eye were excluded from the study. Eyes with a corrected visual acuity of less than 0.5 on a standard ophthalmic examination and eyes with an axial length (ALX) of less than $22.0 \mathrm{~mm}$ or more than $26.0 \mathrm{~mm}$ were also excluded.

\section{Pentacam measurements}

All measurements were obtained under standard dim light conditions and without dilation. The instrument automatically starts the measurement once correct alignment with the corneal apex and focus is achieved. One measurement with the Scheimpflug imaging system takes approximately $2 \mathrm{~s}$, during which time the Scheimpflug camera captures 25 images by rotating 360 degrees around the optical axis of the eye. Three images were evaluated and the one with the best quality was recorded for each eye. CCT measurements and anterior and posterior elevation maps were obtained with this instrument. Once the screening was completed, the Pentacam software automatically recorded the CCT, corneal volume (CV), the volumes of 3, 5, and $7 \mathrm{~mm}^{3}$ (CV3, CV5, and CV7, respectively), and mean keratometry $(\mathrm{mK})$ values. The data obtained from the anterior and posterior maps were evaluated as reported by Uçakhan et al. ${ }^{(8)}$. Accordingly, the Max AE5, Max AD5, AER, and AEDD parameters were calculated from the anterior corneal maps and the Max PE5, Max PD5, PER, and PEDD parameters from the posterior corneal maps. These parameters were then used to evaluate the anterior and posterior aspects of the cornea. These abbreviations of the indices are explained in table 1.

\section{Axial Length measurements}

Proparacaine $\mathrm{HCl}$ 0.5\% drops (Alcaine; Alcon-Couvreur NV, Puurs, Belgium) were used for topical corneal anesthesia before measurement of axial length (Alx). by ultrasound using a Biovision A-Scan V-Plus Echograph (Biovision, Milpitas, CA, USA) equipped with an $8-\mathrm{MHz}$ linear probe. The average of $10 \mathrm{Alx}$ measurements was used for analysis.

\section{Statistical analysis}

SPSS software version 18.0 (SPSS Inc., Chicago, IL, USA) was used for statistical analysis. The Shapiro-Wilk test was used to determine whether the distribution of values was normal. The independent sample $t$-test was used for normally distributed values and the Mann-Whitney $U$ test was used for non-normally distributed values. The chi-square test was used to compare the ratio of males to females between the groups. An a-value of 0.05 indicated a type I error. A probability $(p)$ value of $>0.05$ was considered statistically significant.

\section{RESULTS}

There were 18 males and 17 females in group 1 and 16 males and 19 females in group 2. Table 2 presents the age, BCVA, IOP, sex, axial length, and spherical equivalent values of the patients. There were no statistically significant differences in age, gender, axial length, or spherical equivalent values between two groups ( $p=0.864,0.618$, 0.234 , and 0.850 , respectively).

The CCT and $\mathrm{mK}$ value were obtained directly from the Scheimpflug imaging system and the CV3, CV5, CV7, and total CV data were compared between the two groups. As presented in table 3, there were 
no significant differences in $\mathrm{mK}$ values between the two groups $(p=0.232)$. There was also no statistical difference in CV of the central $3-\mathrm{mm}^{3}$ volume between the two groups $(p=0.172)$. However, there were statistically significant differences in CCT, CV5, CV7, and total $C V$ values between the groups ( $p=0.008,0.003,0.023$, and 0.019 , respectively). The values for all three parameters were lower in the study group than in the control group.

Table 1. Abbreviations

\begin{tabular}{|c|c|}
\hline MaxAE5 & $\begin{array}{l}\text { The maximum elevation value above } \\
\text { the BFS at the central } 5.0 \mathrm{~mm} \text { of the } \\
\text { anterior elevation map obtained by } \\
\text { moving the cursor to the highest point } \\
\text { on the anterior elevation map. }\end{array}$ \\
\hline MaxAD5 & $\begin{array}{l}\text { The maximum depression value below } \\
\text { the BFS at the central } 5.0 \text { mm of the } \\
\text { anterior elevation map obtained by } \\
\text { moving the cursor to the lowest point } \\
\text { on the anterior elevation map. }\end{array}$ \\
\hline AER (anterior elevation ratio) & $\begin{array}{l}\text { Obtained from the anterior elevation } \\
\text { data. The maximum elevation value } \\
\text { above the BFS at the central } 5.0 \mathrm{~mm} \text { of } \\
\text { the anterior elevation map divided by } \\
\text { the BFS (AER Z MaxAE5/BFS). }\end{array}$ \\
\hline $\begin{array}{l}\text { AEDD (anterior elevation depression } \\
\text { difference) }\end{array}$ & $\begin{array}{l}\text { Obtained from the anterior elevation } \\
\text { data. The highest minus lowest value } \\
\text { above and below the best-fit sphere } \\
\text { (BFS) (AEDD Z MaxAE5 _ MaxAD5). }\end{array}$ \\
\hline MaxPD5 & $\begin{array}{l}\text { The maximum depression value below } \\
\text { the BFS at the central } 5.0 \mathrm{~mm}^{3} \text { of the } \\
\text { posterior elevation map obtained by } \\
\text { moving the cursor to the lowest point } \\
\text { on the posterior elevation map. }\end{array}$ \\
\hline MaxPE5 & $\begin{array}{l}\text { The maximum elevation value above } \\
\text { the BFS at the central } 5.0 \mathrm{~mm}^{3} \text { of the } \\
\text { posterior elevation map obtained by } \\
\text { moving the cursor to the highest point } \\
\text { on the posterior elevation map. }\end{array}$ \\
\hline $\begin{array}{l}\text { PEDD (posterior elevation depression } \\
\text { difference) }\end{array}$ & $\begin{array}{l}\text { Obtained from the posterior elevation } \\
\text { data. The highest minus lowest value } \\
\text { above and below the BFS (PEDD = } \\
\text { MaxPE5 - MaxPD5). }\end{array}$ \\
\hline PER (posterior elevation ratio) & $\begin{array}{l}\text { Obtained from the posterior elevation } \\
\text { data. The maximum elevation value } \\
\text { above the BFS at the central } 5.0 \mathrm{~mm}^{3} \text { of } \\
\text { the posterior elevation map divided by } \\
\text { the BFS (PER = MaxPE5/BFS). }\end{array}$ \\
\hline
\end{tabular}

Table 2. Age, sex, axial length and cycloplegic spherical equivalent mean values of the study subjects

\begin{tabular}{lccc}
\hline Patient & $\begin{array}{c}\text { Group } \mathbf{1}(\mathbf{n = 3 5}) \\
\text { (Mean } \pm \text { SD) }\end{array}$ & $\begin{array}{c}\text { Group 2 (n=35) } \\
\text { (Mean } \pm \text { SD) }\end{array}$ & p-value \\
\hline Age, years & $34.68 \pm 15.48$ & $34.11 \pm 12.01$ & 0.864 \\
BCVA & $9 / 10$ & $10 / 10$ & 0.963 \\
IOP & 16 & 17 & 1 \\
Sex & & & \\
$\quad$ Male, n (\%) & $16(45.71 \%)$ & 0.618 \\
Female, n (\%) & $17(51.42 \%)$ & $19(54.28 \%)$ & \\
ALX, mm & $23.50 \pm 0.38$ & $23.39 \pm 0.41$ & 0.234 \\
Spheric equivalent, D & $3.62 \pm 1.75$ & $3.69 \pm 1.51$ & 0.850 \\
\hline
\end{tabular}

$\mathrm{n}=$ number; $\mathrm{SD}=$ standard deviation, $\mathrm{BCVA}=$ best corrected visual acuity; $\mid \mathrm{OP}=$ intraocular pressure; $\mathrm{ALX}=$ axial length; $\mathrm{mm}=$ millimeter; $\mathrm{D}=$ diopter.
The anterior corneal values calculated from the anterior maps obtained via the Scheimpflug imaging system are presented in table 4. There were statistically significant differences in the Max AE5, Max $A D 5, A E R$, and AEDD parameters between the two groups that showed elevation of the anterior cornea $(p=0.001,0.001,0.001$, and 0.001 , respectively). The mean values of these four parameters were greater in the study group than in the control group.

The values calculated from the posterior surface maps of the cornea obtained via the Scheimplug imaging system showing elevation of the posterior cornea are shown in table 5. There were statistically

\begin{tabular}{|c|c|c|c|}
\hline Pentacam data & $\begin{array}{c}\text { Group } 1(n=35) \\
(\text { Mean } \pm \text { SD) }\end{array}$ & $\begin{array}{c}\text { Group } 2(n=35) \\
(\text { Mean } \pm \text { SD) }\end{array}$ & $p$-value \\
\hline Mean K & $40.91 \pm 14.66$ & $43.93 \pm 12.96$ & 0.232 \\
\hline $\mathrm{CCT}, \mu \mathrm{m}$ & $517.06 \pm 36.31$ & $542.66 \pm 41.33$ & $0.008^{*}$ \\
\hline $\mathrm{CV} 3, \mathrm{~mm}^{3}$ & $3.75 \pm 0.27$ & $3.86 \pm 0.37$ & 0.172 \\
\hline $\mathrm{CV} 5, \mathrm{~mm}^{3}$ & $11.00 \pm 0.77$ & $11.59 \pm 0.79$ & $0.003^{*}$ \\
\hline $\mathrm{CV} 7, \mathrm{~mm}^{3}$ & $23.86 \pm 1.86$ & $24.83 \pm 1.60$ & $0.023^{*}$ \\
\hline $\mathrm{CV}, \mathrm{mm}^{3}$ & $57.92 \pm 4.25$ & $60.40 \pm 4.30$ & $0.019^{*}$ \\
\hline
\end{tabular}

* = statistically significant; $\mathrm{n}=$ number; $\mathrm{SD}=$ standard deviation; $\mathrm{K}=$ keratometry; $\mathrm{CCT}=$ central corneal thickness; $\mathrm{CV} 3=$ corneal volume in $3 \mathrm{~mm}^{3} ; \mathrm{CV} 5=$ corneal volume in $5 \mathrm{~mm}^{3}$. $\mathrm{CV} 7=$ corneal volume in $7 \mathrm{~mm}^{3} ; \mathrm{CV}=$ total corneal volume.

Table 4. Comparison of the Max AE5, Max AD5, AER, and AEDD values that were obtained from the anterior elevation map from the Pentacam and that showed the corneal anterior elevation between the two groups

\begin{tabular}{lccc}
\hline Pentacam data & $\begin{array}{c}\text { Group 1 }(\mathbf{n}=\mathbf{3 5}) \\
\text { (Mean } \pm \text { SD) }\end{array}$ & $\begin{array}{c}\text { Group 2 (n=35) } \\
\text { (Mean } \pm \text { SD) }\end{array}$ & p-value \\
\hline Max AE5, $\mu \mathrm{m}$ & $12.22 \pm 6.66$ & $7.51 \pm 4.23$ & $0.001^{*}$ \\
Max AD5, $\mu \mathrm{m}$ & $-13.11 \pm 6.68$ & $-8.31 \pm 5.17$ & $0.001^{*}$ \\
AER & $1.42 \pm 0.95$ & $0.96 \pm 0.62$ & $0.001^{*}$ \\
AEDD, $\mu \mathrm{m}$ & $24.80 \pm 11.82$ & $15.02 \pm 9.00$ & $0.001^{*}$ \\
\hline
\end{tabular}

* = statistically significant; $n=$ number; $S D=$ standard deviation; MaxAE5= the maximum elevation value above the BFS at the central $5.0 \mathrm{~mm}^{3}$ of the anterior elevation map: MaxAD5= the maximum depression value below the BFS at the central $5.0 \mathrm{~mm}^{3}$ of the anterior elevation map; $A E R=$ anterior elevation ratio obtained from the anterior elevation data; $\mathrm{AEDD}=$ anterior elevation depression difference obtained from the anterior elevation data.

Table 5. Comparison of the Max AE5, Max AD5, AER, and AEDD values that were obtained from the posterior elevation map from the Pentacam and that showed the corneal posterior elevation between the two groups

\begin{tabular}{lccc}
\hline Pentacam data & $\begin{array}{c}\text { Group } \mathbf{1}(\mathbf{n}=\mathbf{3 5}) \\
\text { (Mean } \pm \text { SD) }\end{array}$ & $\begin{array}{c}\text { Group 2 }(\mathbf{n = 3 5}) \\
\text { (Mean } \pm \text { SD) }\end{array}$ & P \\
\hline Max PE5, $\mu \mathrm{m}$ & $26.28 \pm 15.56$ & $19.74 \pm 11.40$ & 0.066 \\
Max PD5, $\mu \mathrm{m}$ & $-29.17 \pm 13.15$ & $-24.51 \pm 12.32$ & 0.140 \\
PER & $4.21 \pm 2.45$ & $2.88 \pm 1.51$ & $0.001^{*}$ \\
PEDD, $\mu \mathrm{m}$ & $54.77 \pm 27.06$ & $43.17 \pm 20.83$ & $0.048^{*}$ \\
\hline
\end{tabular}

* = statistically significant. $\mathrm{n}$, number; $\mathrm{SD}=$ standard deviation; MaxPD5= the maximum depression value below the BFS at the central $5.0 \mathrm{~mm}^{3}$ of the posterior elevation map; MaxPE5= the maximum elevation value above the BFS at the central $5.0 \mathrm{~mm}^{3}$ of the posterior elevation map; $\mathrm{PER}=$ posterior elevation ratio obtained from the posterior elevation data; $\mathrm{PEDD}=$ posterior elevation depression difference obtained from the posterior elevation data. 
significant differences in the PER and PEDD parameters between the two groups ( $p=0.001$ and 0.048 , respectively), while there were no significant differences in Max PE5 and Max PD5 values between the two groups ( $p=0.066$ and 0.14 , respectively).

\section{DISCUSSION}

There is a relationship between the optic disc and cornea, which are the anterior and posterior windows of the sclera to the outside. A marked relationship between abnormal optic disc shape and abnormal corneal configuration has been reported in the literature ${ }^{(6)}$. Thick corneas have been shown to be present with optic disc drusen, indicating a relationship between development of the optic nerve head and corneal thickness ${ }^{(9)}$. These findings indicate that factors that play roles in corneal development also play roles in optic disc development. A previous study reported a relationship between cornea and optic disc dimensions and that the larger the cornea, the larger the optic disc ${ }^{(10)}$. Another study found a reverse relationship between CCT and the optic nerve area in primary open angle glaucoma patients and this relationship was shown to result in larger optic nerve areas with thinner corneas ${ }^{(11)}$.

TDS is a congenital optic disc anomaly that affects the anterior and posterior segments of the eye. A significant relationship has been found between an abnormal optic disc shape and abnormal corneal structure in TDS cases $^{(6)}$. Another study found no statistically significant relationship between CCT values of TDS patients and normal controls ${ }^{(12)}$. However, they found that the CCT was $6-\mu \mathrm{m}$ thicker in TDS patients than in the control group. Dehghani et al. ${ }^{(4)}$ also found no statistically significant relationship in corneal thickness between the TDS and control groups, although CCT values were greater in TDS cases. In contrast, we found significantly smaller CCT values in eyes with TDS than in those in the control group (517.06 \pm 36.31 vs. $542.66 \pm$ 41.33 microns, respectively, $p=0.008$ ). We believe that the difference in CCT between our study and these previous reports is due to the technique used to measure corneal thickness and racial differences of the included subjects. The A-scan ultrasound used in the literature is highly user-dependent compared to the Pentacam system, which can also influence the results ${ }^{(13)}$. The technique used in the present study provides more reliable results in this respect. Studies have also shown that CCT can vary between subjects of different races ${ }^{(14,15)}$.

The parameters for evaluation of CV were also checked in this study. There was no difference in the CV3 value while there were statistically significant differences in the CV5, CV7, and CV values between the two groups, which indicated that CV is decreased and the cornea is thinner in eyes with TDS. We therefore believe that the lower volume in the peripheral cornea than in the central cornea in TDS cases can increase the risk of ectasia following refractive surgery.

Current technology has facilitated the detection of ectasia of the anterior and posterior aspects. Identification of elevations of the anterior and posterior corneal surfaces is especially important for refractive surgery. It has also been reported that elevation of the posterior cornea is important for early detection of keratoconus in addition to anterior corneal elevation ${ }^{(16,17)}$. We found a significant difference in anterior curvature changes of the cornea between the control and TDS groups in this study. We also found changes in elevation of the posterior corneal surface, although these changes were not as significant as those in the anterior surface. Since this is the first study to compare the degree of elevation of the anterior and posterior cornea in TDS cases, we were unable to compare our data with other data sets in the literature. However, we believe these corneal elevations could be important in TDS patients who are candidates for refractive surgery.

The main difference of this study from others in the literature is the use of the Scheimpflug imaging system to evaluate the anterior and posterior surfaces, and volumes of the cornea in detail in TDS cases. Prior studies only evaluated refractive and pachymetric measurements of the cornea. The Scheimpflug imaging system uses the elevation-based tomography principle and therefore provides accurate and reliable data on the actual shape of the cornea, independent of position, orientation and axis ${ }^{(18)}$. It therefore enables a much more detailed evaluation of the cornea than do refractive or ultrasonographic pachymetry measurements.

There were some limitations to this study. The main limitations were the small number of cases and the lack of blinding during the examinations. Multicenter studies with larger patient cohorts may provide more valuable results. Another limitation was that the study and control groups consisted of Caucasians only. Thus, future studies of multiracial study groups will provide more valuable information.

In conclusion, we performed a detailed evaluation of the cornea in eyes with TDS and found that CCT was lower, the cornea volume was decreased especially in the peripheral regions, and there were important changes, especially in the anterior corneal elevation in eyes with TDS, as compared to normal eyes. The decreased peripheral CV together with anterior corneal elevation in TDS cases can cause serious problems during refractive surgery procedures resulting in $\mathrm{CV}$ loss. We therefore feel that the cornea should be evaluated more carefully in eyes with TDS before refractive surgery. Repeating this study with a larger cohort could reinforce the results.

\section{REFERENCES}

1. Apple DJ, Rabb MF, Walsh PM. Congenital anomalies of the optic disc. Surv Ophthalmol. 1982;27(1):3-41

2. Young SE, Walsh FB, Knox DL. The tilted disc syndrome. Am JOphthalmol. 1976;82(1): 16-23.

3. Gündüz A, Evereklioğlu C, Er H, Hepșen IF. Lenticular astigmatism in tilted disc syndrome. J Cataract Refract Surg. 2002;28(10):1836-40.

4. Dehghani C, Nowroozzadeh MH, Shankar S, Razeghinejad MR. Ocular refractive and biometric characteristics in patients with tilted disc syndrome. Optometry. 2010;81(12): 688-94.

5. Bozkurt B, Irkec M, Gedik S, Orhan M, Erdener U.Topographical analysis of corneal astigmatism in patients with tilted-disc syndrome.Cornea. 2002;21(5):458-62.

6. Jonas JB, Kling F, Grundler AE. Optic disc shape, corneal astigmatism, and amblyopia. Ophthalmology. 1997;104(11):1934-7.

7. Pakravan M, Parsa A, Sanagou M, Parsa CF. Central corneal thickness and correlation to optic disc size: a potential link for susceptibility to glaucoma. Br J Ophthalmol. 2007; 91(1):26-8.

8. Uçakhan ÖÖ, Cetinkor V, Özkan M, Kanpolat A. Evaluation of Scheimpflug imaging parameters in subclinical keratocunus, keratocunus, and normal eyes. J Cataract Refract Surg. 2011;37(6):1116-24

9. Dohadwala AA, Damji KF. Familial occurrence of artefactual ocular hypertension from thick corneas and of primary open angle glaucoma in a French Canadian kindred. Ophthalmic Genet. 2000;21(1):1-7.

10. Jonas JB, Konigsreuther KA. Macrodiscs in eyes with flat and large corneas. Ger J Ophthalmol. 1994;3(3):179-81.

11. Insull E, Nicholas S, Ang GS, Poostchi A, Chan K, Wells A. Optic disc area and correlation with central corneal thickness, corneal hysteresis and ocular pulse amplitude in glaucoma patients and controls. Clin Experiment Ophthalmol. 2010;38(9):839-44.

12. Ornek K, Ozdemir M. Central corneal thickness in tilted disc syndrome. Optom Vis Sci. 2008;85(5):E350-52.

13. Kuerten D, Plange N, Koch EC, Koutsonas A, Walter P, Fuest M.Central corneal thickness determination in corneal edema using ultrasound pachymetry, a Scheimpflug camera, and anterior segment OCT. Graefes Arch Clin Exp Ophthalmol. 2015;253(7):1105-9.

14. Yo C, Ariyasu RG. Racial differences in central corneal thickness and refraction among refractive surgery candidates. J Refract Surg. 2005;21(2):194-7.

15. Aghaian E, Choe JE, Lin S, Stamper RL.Central corneal thickness of Caucasians, Chinese Hispanics, Filipinos, African Americans, and Japanese in a glaucoma clinic. Ophthalmology. 2004;111(12):2211-9.

16. Piñero DP, Alió JL, Alesón A, Escaf Vergara M, Miranda M. Corneal volume, pachymetry, and correlation of anterior and posterior corneal shape in subclinical and different stages of clinical keratoconus. J Cataract Refract Surg. 2010;36(5):814-25.

17. Nilforoushan MR, Speaker M, Marmor M, Abramson J, Tullo W, Morschauser D, Latkany R. Comparative evaluation of refractive surgery candidates with Placido topography, Orbscan II, Pentacam, and wavefront analysis. J Cataract Refract Surg. 2008;34(4):623-31.

18. Miháltz K, Kovács I, Takács A, Nagy ZZ.Evaluation of keratometric, pachymetric, and elevation parameters of keratoconic corneas with pentacam.Cornea. 2009;28(9):976-80. 